\title{
Imipramine alters the sterol profile in Leishmania amazonensis and increases its sensitivity to miconazole
}

\author{
Valter Viana Andrade-Neto, Thaís Martins Pereira, Marilene do Canto-Cavalheiro \\ and Eduardo Caio Torres-Santos*
}

\begin{abstract}
Background: Imipramine, a tricyclic antidepressant widely used clinically, has other pharmacological effects, such as antileishmanial activity. Tricyclic antidepressants interact with lipid bilayers, and some studies have shown that imipramine inhibits methyltransferases. Leishmania spp. produces compounds with an ergostane skeleton instead of a cholesterol skeleton, and the inhibition of enzymes of the sterol biosynthesis pathway is an interesting therapeutic target. Among these enzymes, C-24 methyltransferase has been suggested to play an essential role, as its inhibition kills the parasites. In this context, we investigated whether imipramine alters the biosynthesis of sterols in L. amazonensis and evaluated the efficacy of imipramine alone and in combination with miconazole, a classical inhibitor of another step in this pathway.
\end{abstract}

Methods: To analyze the interference of imipramine with sterol metabolism, promastigotes of $L$. amazonensis were cultured with medium alone, 15 or $30 \mu \mathrm{M}$ imipramine or $4 \mu \mathrm{M}$ miconazole, and their lipids were extracted with methanol/chloroform/water (1:0.5:0.4 v/v) and analyzed by GC/MS. To assess the antileishmanial activity of the treatments, promastigotes of $L$. amazonensis were incubated with various concentrations of imipramine up to $100 \mu \mathrm{M}$ and up to $24 \mu \mathrm{M}$ miconazole. Promastigotes were also treated with the combination of imipramine and miconazole at concentrations up to $12.5 \mu \mathrm{M}$ of imipramine and $24 \mu \mathrm{M}$ of miconazole. Parasite growth was evaluated by the MTT assay. The fractional inhibitory concentration index (FICl) was calculated to determine whether there were synergistic effects. Peritoneal macrophages with and without L. amazonensis infection were treated with miconazole $(0-16 \mu \mathrm{M})$ or imipramine $(0$ to $50 \mu \mathrm{M})$ for 72 hours. For assays of the combined treatment in amastigotes, the concentration of imipramine was fixed at $12.5 \mu \mathrm{M}$ and various concentrations of miconazole were used up to $16 \mu \mathrm{M}$. The infection rate was determined by counting the infected macrophages under a light microscope.

Findings: Promastigotes treated with imipramine accumulated cholesta-5,7,22-trien-3 $\beta$-ol and cholesta-7-24-dien-3 3-ol, sterols that normally increase after treatment with classical inhibitors of $\mathrm{C}-24$ methyltransferase. The $\mathrm{IC}_{50}$ of miconazole in promastigotes decreased when it was used in combination with imipramine, resulting in an additive effect, with a FICl value of 0.83 . Imipramine also showed activity against intracellular amastigotes and enhanced the activity of miconazole, without apparent toxicity to the host cells.

Conclusions: Imipramine was confirmed to have antileishmanial activity in both forms of the parasite, affecting the sterol biosynthesis of the organisms. Using imipramine in combination with azoles may be advantageous for the treatment of leishmaniasis.

Keywords: Leishmania, Imipramine, Sterols

\footnotetext{
* Correspondence: ects@ioc.fiocruz.br

Laboratório de Bioquímica de Tripanosomatídeos, Instituto Oswaldo Cruz,

FIOCRUZ, Avenida Brasil 4365, Manguinhos, Rio de Janeiro, Brazil
} 


\section{Background}

Leishmaniasis is a disease caused by parasites of the genus Leishmania, unicellular eukaryotes belonging to class Kinetoplastea and family Trypanosomatidae. Leishmania spp. are transmitted by more than 20 species of sandflies of the genera Phlebotomus and Lutzomyia [1]. Leishmaniasis is a non-contagious infectious disease that can affect the skin and mucous membranes (cutaneous leishmaniasis) or internal organs (visceral leishmaniasis) [2, 3]. Endemic transmission of leishmaniasis is known to occur in 98 countries on five continents. It has been estimated that there were more than 58,000 cases of visceral leishmaniasis and 220,000 cases of cutaneous leishmaniasis [4].

Since the 1940s, the main treatment for leishmaniasis has included antimony derivatives that are commercially available in two formulations, $\mathrm{N}$ - methylglucamine antimoniate (meglumine antimoniate, Glucantime ${ }^{\odot}$ ) and sodium stibogluconate (Pentostam ${ }^{\odot}$ ) [5]. These drugs have many toxic effects, including cardiac, hepatic, pancreatic and renal toxicity, and should be used with caution and with clinical and laboratory monitoring in patients with heart or liver disease [6]. The efficiency of antimony may vary, and treatment protocols are determined depending on the region. Many cases of resistance have been reported, making treatment difficult [7]. Miltefosine, the only oral treatment, has been prescribed in India for visceral leishmaniasis for more than a decade and was recently approved by the FDA for all forms of this disease, but some concerns about resistance and teratogenicity have been raised $[8,9]$. Other drugs, such as pentamidine and amphotericin $\mathrm{B}$, may be used if resistance to the first-line treatment occurs, although these have major toxicity [5]. Furthermore, no vaccine for human use has been developed to date, although some studies have been carried out, such as a study of the protective role of serine proteases in the parasite [10]. Thus, there is a need to search for new strategies to control leishmaniasis.

Imipramine, a tricyclic antidepressant widely used in the clinical setting, is used in the treatment of severe chronic depression because it inhibits5-hydroxytryptamine (serotonin) and norepinephrine reuptake [11]. Beyond its actions on the central nervous system, imipramine also has other biological effects, such as immunosuppressive properties through the modulation of inflammatory cytokine production and the induction of autophagic death in tumor cells [12, 13]. The antileishmanial effects of imipramine and its analogs were first demonstrated in the 1980s in promastigotes and amastigotes of $L$. donovani and $L$. major [14]. Imipramine also exhibited activity against antimony-resistant intracellular amastigotes without affecting the host cells. Additionally, oral treatment with imipramine reduced the parasite burden of visceral leishmaniasis in hamsters [15].
Tricyclic antidepressants have high affinity for the phosphatidylcholine and phosphatidylethanolamine in lipid membranes, causing changes in lipid-protein interactions [16]. Another interesting feature of imipramine is its effect on methyltransferases. Imipramine has been described to inhibit the activity of catecholO-methyltransferase (COMT), DNA methyltransferase and the methylation of phospholipids in the plasma membrane $[17,18]$.

The sterol biosynthesis pathway of trypanosomatids has diverged from that in mammalians such that these parasites produce ergosterol derivatives instead of cholesterol [19]. It is assumed that this biosynthetic pathway is essential in Leishmania because pharmacological inhibition of different steps results in the death of the parasite [20-25]. Methylation by C-24methyltranferase is one of final steps of sterol biosynthesis in Leishmania, and this reaction does not occur in mammalians. Inhibition of this enzyme by azasterols causes the accumulation of cholestane derivatives and leads to parasite death [26].

Here we investigated the effects of imipramine on the sterol biosynthesis of L. amazonensis and its leishmanicidal activity in combination with miconazole, a wellknown inhibitor of this pathway.

\section{Methods}

\section{Drugs}

Miconazole and imipramine were provided by SigmaAldrich (St. Louis, USA) and stored at $-20^{\circ} \mathrm{C}$ in DMSO (Sigma-Aldrich) stock solution (10 mM).

\section{Maintenance and cultivation of parasites}

Promastigotes of Leishmania amazonensis (strain MHOM/ $\mathrm{BR} / 77 / \mathrm{LTB} 0016)$ were maintained at $26{ }^{\circ} \mathrm{C}$ in RPMI medium (Sigma- Aldrich) supplemented with $10 \%$ fetal bovine serum (FBS), $100 \mu \mathrm{g} / \mathrm{ml}$ streptomycin, $100 \mathrm{U} / \mathrm{ml}$ penicillin and $5 \mathrm{mg} / \mathrm{ml}$ hemine. Subcultures were performed twice a week until the tenth passage. Afterwards, old cultures were discarded and fresh parasites were obtained from infected BALB/c mice.

\section{Antipromastigote activity}

Promastigotes of $L$. amazonensis were maintained in cell culture flasks at $26{ }^{\circ} \mathrm{C}$ in RPMI medium without phenol red (Sigma- Aldrich) supplemented as described above. Experiments were performed on promastigotes in 96-well plates, with an initial inoculum of $1.0 \times 10^{6} \mathrm{cells} / \mathrm{ml}$ and compound concentrations of up to $24 \mu \mathrm{M}$ of miconazole and to $100 \mu \mathrm{M}$ of imipramine. In the combination experiments, the concentrations were up to $24 \mu \mathrm{M}$ of miconazole and $12.5 \mu \mathrm{M}$ of imipramine. Plates were incubated at $26{ }^{\circ} \mathrm{C}$ for 72 hours. After this period, parasite growth was evaluated by adding $10 \%$ tetrazolium salt (MTT, SigmaAldrich) $(5 \mathrm{mg} / \mathrm{ml})$ per well. The plates were incubated at 
$26{ }^{\circ} \mathrm{C}$ for a further hour, and formazan crystals were dissolved by adding $80 \mu \mathrm{l}$ of DMSO to each well. The reaction was analyzed using a spectrophotometer at $570 \mathrm{~nm}$ wavelength. $\mathrm{IC}_{50}$ values were obtained by non-linear regression using the GraphPad Prism 6 software (GraphPad Software Inc., La Jolla, USA). The fractional inhibitory concentration (FIC) determined to analyze whether the combination treatments were synergistic was calculated as follows: $\mathrm{FIC}=\mathrm{IC}_{50}$ of drug $\mathrm{A}$ in combination/ $/ \mathrm{IC}_{50}$ of drug A alone $+\mathrm{IC}_{50}$ of drug $\mathrm{B}$ in combination/ $/ \mathrm{IC}_{50}$ of drug $\mathrm{B}$ alone. The arithmetic mean of the FICs obtained for each concentration was interpreted according to published guidelines: synergy ( $\mathrm{FIC} \leq 0.5)$, antagonism (FIC $\geq 4.0$ ) and additive effect (no interaction) $(0.5<\mathrm{FIC}<4.0)$ [27].

\section{Antiamastigote activity}

Peritoneal macrophages from BALB/c mice were infected with promastigotes of L. amazonensis in Lab-Tek chambers (Nunc, Roskilde, Denmark) and kept at $37{ }^{\circ} \mathrm{C}$. After four hours, the chambers were washed, and the cultures were treated with miconazole alone or in combination with imipramine in supplemented RPMI medium for 72 hours. Various concentrations were used for these studies, with up to $16 \mu \mathrm{M}$ of miconazole and $50 \mu \mathrm{M}$ of imipramine. In the combination assays, the concentration of imipramine was fixed at $12.5 \mu \mathrm{M}$ and the concentration of miconazole varied, with the maximum concentration being $16 \mu \mathrm{M}$. After incubation, the slides were stained, and the infection rate was determined by counting the infected macrophages under a light microscope. The infection rate was calculated using the formula: \% infected macrophages $\times$ number of amastigotes/number of total macrophages.

\section{Toxicity to macrophages}

Mouse peritoneal macrophages in 96-well plates were treated with imipramine and miconazole alone or in combination for 72 hours at $37^{\circ} \mathrm{C}$. After this period, the cell viability was evaluated by adding $10 \%$ tetrazolium salt (MTT) $(5 \mathrm{mg} / \mathrm{ml})$ to each well. The plates were incubated at $37{ }^{\circ} \mathrm{C}$ for another four hours, and the resulting formazan crystals were dissolved by adding $80 \mu \mathrm{l}$ DMSO to each well. The plates were then read at $570 \mathrm{~nm}$. The results were expressed as the percentage of viable cells compared to the untreated control.

\section{Extraction of lipids}

Lipids from promastigotes of $L$. amazonensis were extracted using the method reported by Bligh \& Dyer [28]. Briefly, samples were pelleted, and a solution of methanol, chloroform and water (2:1:0.5 v/v) was added. After stirring the mixture for one hour, the samples were centrifuged for $20 \mathrm{~min}$ at 3,000 rpm and the supernatant containing the lipids was separated from the precipitate. The precipitate was subjected to a second extraction under the same conditions. The supernatants were combined, and methanol/ chloroform/water (1:0.5:0.4 v/v) was added. After $40 \mathrm{sec}-$ onds of stirring, the material was centrifuged $(3,000 \mathrm{rpm} /$ $30 \mathrm{~min}$ ) again. The lower layer (organic) containing the lipids was then separated with the aid of a glass syringe and was transferred to a $1.5 \mathrm{ml}$ tube resistant to organic solvents (Axygen Scientific, Inc., Union City, CA, USA). The solvent was evaporated under an $\mathrm{N}_{2}$ flux, and the lipids were analyzed by gas chromatography- mass spectrometry (GC/MS), as described below.

\section{Analysis of the sterol profile by gas chromatography coupled with mass spectrometry (GC/MS)}

Promastigotes of L. amazonensis were cultured with 15 or $30 \mu \mathrm{M}$ imipramine or $4 \mu \mathrm{M}$ miconazole or in culture medium alone. After 72 hours, $1 \times 10^{8}$ parasites from each culture were washed three times in cold PBS (pH 7.5), and the sterols were extracted as described in Section 3.6. The samples were injected into a GC/MS - QP2010 Ultra Machine (Shimadzu Scientific Instruments, Tokyo, Japan). After injection, the column temperature was maintained at $50{ }^{\circ} \mathrm{C}$ for one minute and then increased to $270{ }^{\circ} \mathrm{C}$ at a rate of $10{ }^{\circ} \mathrm{C} / \mathrm{min}$ and finally to $300{ }^{\circ} \mathrm{C}$ at a rate of $1{ }^{\circ} \mathrm{C} /$ min. The flow of the carrier gas $(\mathrm{He})$ was kept constant at $1.1 \mathrm{ml} / \mathrm{min}$. The temperatures of the injector and detector were $250{ }^{\circ} \mathrm{C}$ and $280{ }^{\circ} \mathrm{C}$, respectively [29].

\section{Ethical approval}

Macrophages from BALB/c mice were obtained in accordance with protocols approved by the Ethics Committee for Animal Use of the Instituto Oswaldo Cruz (L026/2015).

\section{Results and discussion}

Imipramine has effects on the cell growth and membrane functions of $L$. donovani and L. major [14]. Antidepressants cause lethal disruption of their membrane function, reductions in mitochondrial proton motive force and apoptosis in Leishmania spp. [30]. In addition to the effects on the parasite itself, imipramine is also a potent inducer of TNF- $\alpha$ in macrophages, which is an important cytokine for antileishmanial defense [31]. Tricyclic antidepressants (imipramine, desipramine, amitriptyline and nortriptyline) are amphiphilic molecules that accumulate in membranes and alter their biophysical characteristics $[16,32]$. Imipramine has also been demonstrated to inhibit the three main classes of methyltransferases $(\mathrm{N}, \mathrm{O}$ and $\mathrm{C}$ methyltransferases). The activity of phosphatidylethanolamine $\mathrm{N}$-methyltransferase was also found to be inhibited by imipramine and chlorpromazine [33]. Moreover, imipramine has inhibitory effects on erythrocyte catechol-Omethyltransferase and indirectly inhibits DNA methylation by cytosine C-methyltransferase [17, 34]. 
Table 1 Effects of imipramine and miconazole on the sterol composition of L. amazonensis promastigotes

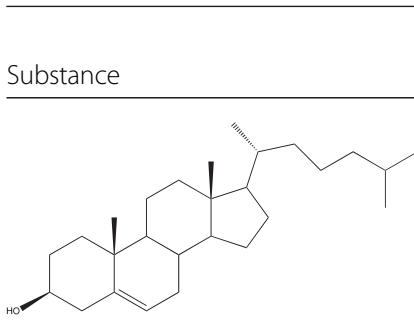

(1) Cholesterol (exogenous)<smiles>CC(C)C/C=C/C(C)C1CCC2C3=CC=C4C[C@@H](O)CCC4(C)C3CCC21C</smiles>

(2) Cholesta-5,7,22-trien-3 $\beta$-ol<smiles>CC(C)=CCCC(C)C1CCC2C3=CCC4C[C@@H](C)CCC4(C)C3CC[C@@]21C</smiles>

(3) Cholesta-7-24-dien-3 $\beta$-ol<smiles>C=C(CC[C@@H](C)C1CC[C@]2(C)C3=C(CC[C@]12C)[C@@]1(C)CC[C@H](O)CC1CC3)C(C)C</smiles>

(4) 14a-metilergosta-8,24 (24 $\left.{ }^{1}\right)$-dieno-3ß-ol<smiles>C=C(CCC(C)C1CCC2C3=CC=C4C[C@@H](C)CCC4(C)C3CCC21C)C(C)C</smiles>

(5) Ergosta-5,7,24-trien-3 $\beta$-ol (dehydroepisterol)<smiles>C=C(CC[C@H](C)C1CCC2C3=CCC4C[C@@H](C)CC[C@]4(C)C3CC[C@]21C)C(C)C</smiles>

(6) Ergosta-7,24-dien-3 $\beta$-ol (Episterol)<smiles>C=C(CC[C@@H](C)C1CC[C@]2(C)C3=C(CC[C@]12C)[C@@]1(C)CC[C@H](O)C[C@]1(C)CC3)C(C)C</smiles> 
Considering the affinity of imipramine for membranes and its effects on methyltransferases, we hypothesized that imipramine may interfere with the sterol metabolism of parasites. Therefore, we analyzed the sterol composition of promastigotes of L. amazonensis when they were exposed to imipramine. Table 1 shows the results of an analysis of the relative amount of each sterol. The promastigotes treated with imipramine showed a decrease in cholesterol (1) and in the ergostane-derived sterols (C24methylated sterols) ergosta-5,7,24-trien-3 $\beta$-ol (dehydroepisterol) (5) and ergosta-7,24-dien-3 $\beta$-ol (episterol) (6). Interestingly, we also observed a concomitant accumulation of cholestane-derived sterols (C24-demethylated sterols), cholesta-5,7,22-trien-3ß-ol (2), cholesta-7-24-dien3ß-ol (3).

Azasterols inhibit the C24 sterol methyltransferase, an enzyme required for the production of the typical ergostane- and stigmastane-based sterols, which are not found in mammalian cells [35]. Azasterols interfere with the sterol biosynthesis of T. cruzi and Leishmania spp., resulting in cell growth arrest and death [36]. The treatment of L. donovani promastigotes with azasterol altered their sterol profile, leading to a global decrease in 24-methylsterols and an increase in demethylated sterols [37]. This effect is similar to that observed following the treatment with imipramine (Table 2), suggesting that it occurs via a similar mechanism of action.

Various inhibitors of sterol biosynthesis (azoles, statins and allylamines) have been extensively studied in Leishmania spp., confirming that this pathway is an excellent target for the chemotherapy of leishmaniasis $[19,21-25,37,38]$. As seen in Table 1 , treatment with miconazole disturbs the sterol synthesis in a different fashion than imipramine, causing the accumulation of C14 methyl sterols, $14 \alpha$-metilergosta-8,24 (24 $\left.{ }^{1}\right)$-dieno-3 $\beta$-ol (4) and obtusofoliol (7), sterols that typically accumulate following the inhibition of C14 demethylase [20].

Using a combination of drugs that act on different points of the same pathway has been noted to represent an interesting strategy for antimicrobial chemotherapy $[20,21]$. Haughan et al. demonstrated that the combination of lovastatin (an HMGCoA reductase inhibitor) and miconazole (C14-demethylase inhibitor) led to synergistic activity against promastigotes of L. amazonensis [23].

Table 2 Relative proportions of 24-methylated and 24demethylated sterols from L. amazonensis promastigotes treated with imipramine

\begin{tabular}{llll}
\hline & \multicolumn{3}{l}{ Imipramine } \\
\cline { 2 - 4 } & 0 & $15 \mu \mathrm{M}$ & $30 \mu \mathrm{M}$ \\
\hline \% 24-alkylated & 90.51 & 61.69 & 50.16 \\
\% 24-nonalkylated & 0 & 30.55 & 44.44 \\
\hline
\end{tabular}

Therefore, since both drugs (imipramine and miconazole) interfere with the sterol synthesis pathway, but generate different aberrant metabolites, we decided to evaluate the effects of their combination on the parasite growth. The antileishmanial activity of imipramine alone and in combination with miconazole in the promastigotes of L. amazonensis is shown in Fig. 1a and b. The effects of the combination were expressed graphically as an isobologram, where the $\mathrm{IC}_{50}$ values of the drugs alone and in combination were plotted. The fractional inhibitory concentration index (FICI) was calculated to classify the interaction as synergistic, antagonistic or additive. As expected, miconazole was active against promastigotes, with an $\mathrm{IC}_{50}$ of $4.7 \pm 1.03 \mu \mathrm{M}$. Imipramine also proved to be active alone, with an $\mathrm{IC}_{50}$ of $28.63 \pm$ $1.2 \mu \mathrm{M}$. The combination resulted in an additive effect, as observed in the isobologram, with a FICI value of 0.83 (Fig. 1b-c), suggesting that imipramine and miconazole can be used in combination, as no antagonistic effect was observed.

Before testing the effects on intracellular amastigotes, we evaluated the toxicity of imipramine alone and in combination with miconazole in host cells. Uninfected peritoneal macrophages showed no signs of toxicity when incubated with imipramine alone at concentrations less than $50 \mu \mathrm{M}$ (Fig. 2a). Miconazole also showed no toxic effects, even when used in combination with imipramine (Fig. 2b-c).

In the next step, we assessed the activity of imipramine against intracellular amastigotes, the clinically significant stage of the parasite. The $\mathrm{IC}_{50}$ was found to be $13.32 \pm$ $1.1 \mu \mathrm{M}$ (Fig. 3a). Due to the experimental difficulty associated with performing a "checkerboard" approach to draw isobolograms for antiamastigote activity, we fixed the concentration of imipramine at $12.5 \mu \mathrm{M}$ and varied the concentration of miconazole to calculate the $\mathrm{IC}_{50}$ and $\mathrm{IC}_{90}$ values of the combination. When used in combination with imipramine, the $\mathrm{IC}_{50}$ of miconazole was reduced from $2.2 \pm 0.2 \mu \mathrm{M}$ to $0.5 \pm 0.1 \mu \mathrm{M}$ and the $\mathrm{IC}_{90}$ was reduced from $3.9 \pm 0.2 \mu \mathrm{M}$ to $2.2 \pm 0.1 \mu \mathrm{M}$ (Fig. $3 \mathrm{~b}$ ).

In addition to having its own machinery for sterol biosynthesis, Leishmania also uptakes a significant amount of exogenous cholesterol, mainly through the endocytosis of LDL particles [39]. Andrade-Neto et al. have described that the inhibition of the sterol pathway in L. amazonensis increases the intake of cholesterol from the culture medium [40]. Interestingly, imipramine has been reported to block the release of cholesterol from lysosomes in mammalian cells, especially from the endocytosis of LDL particles, preventing its distribution for use by the cell $[41,42]$. Therefore, it is possible that imipramine is interfering with both the biosynthesis and utilization of exogenous sources of sterols, so further studies are needed to address this issue. 


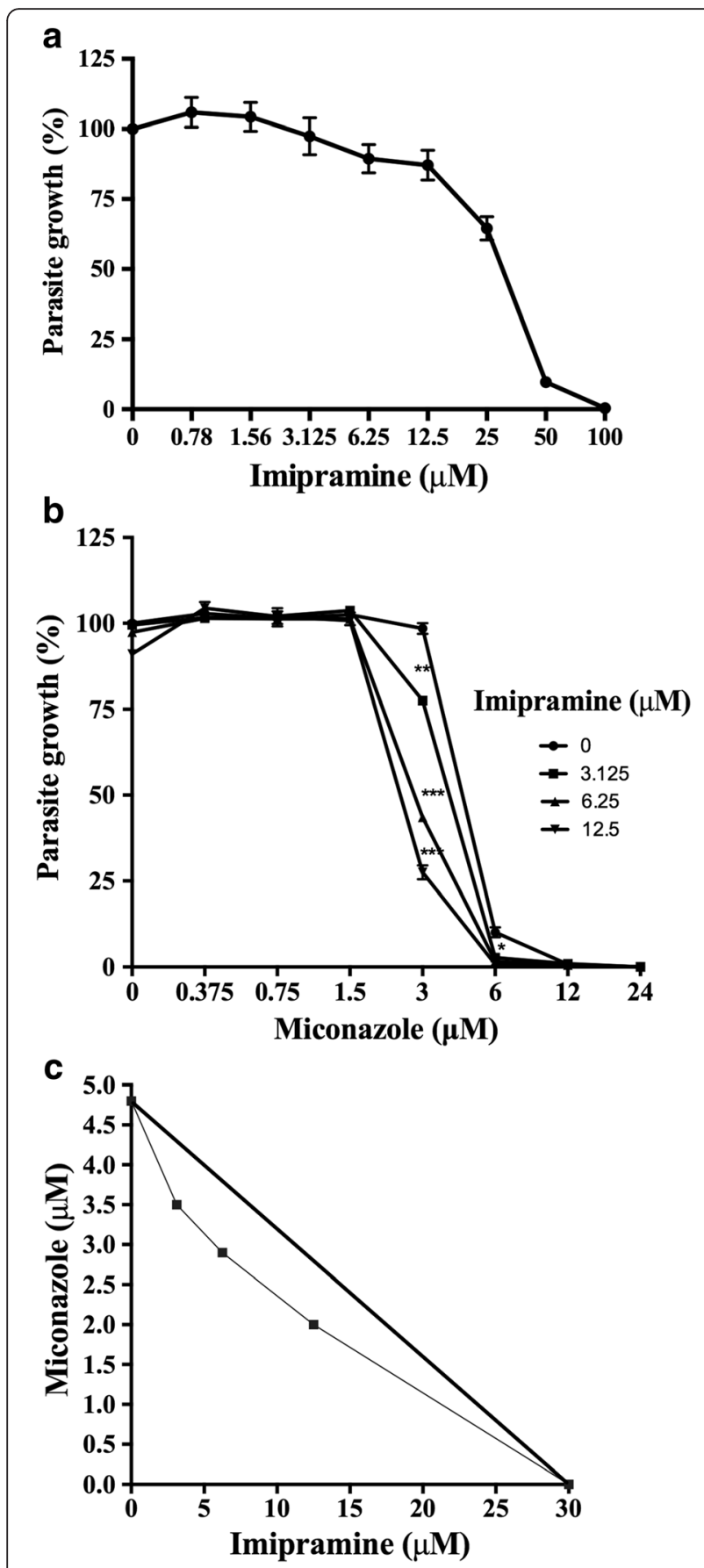

Fig. 1 Antipromastigote activity of imipramine, miconazole and their combination. Promastigotes of $L$. amazonensis were incubated with different concentrations of imipramine with or without miconazole for 72 hours at $26^{\circ} \mathrm{C}$. a imipramine, $\mathbf{b}$ imipramine + miconazole $\mathbf{c}$ an isobologram. Each plotted point in the isobologram is the $I_{50}$ of the drugs alone or in combination. The straight line connecting the individual $I C_{50}$ values represents the theoretical line of additivity. The experiments were performed in triplicate, $n=3$. The graphs are representative of one experiment, and the standard deviations are shown. The graphics and $\mathrm{IC}_{50}$ values were obtained using the GraphPad Prism 4 software. ${ }^{*} P<0.05$, ** $P<0.01$, *** $P<0.001$
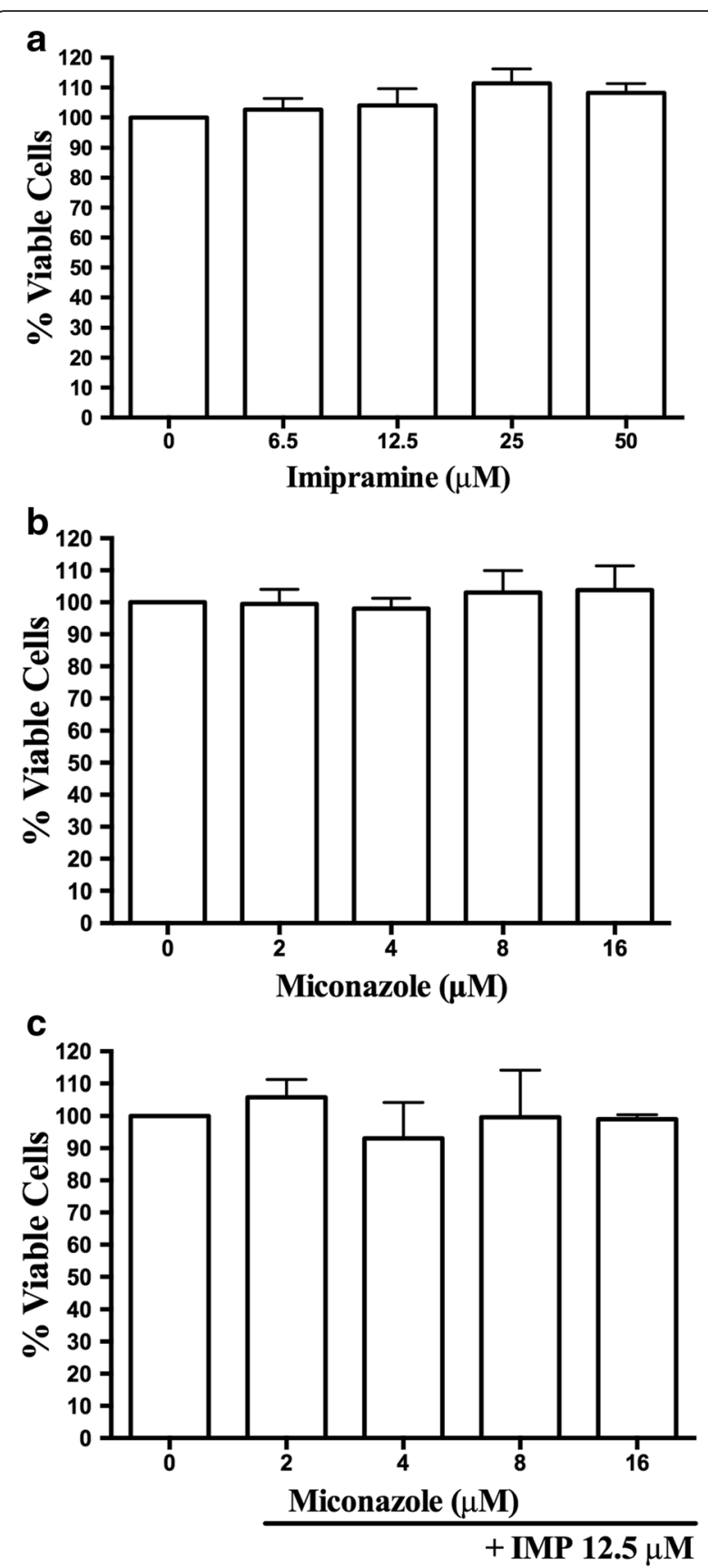

Fig. 2 Effect on the toxicity of inhibitors peritoneal macrophages. Uninfected macrophages were incubated with imipramine, miconazole alone or the combination of the two agents for 72 hours at $37^{\circ} \mathrm{C}$. After this period, the cells were incubated with MTT for 1 hour at $37^{\circ} \mathrm{C}$, and the absorbance was read at $570 \mathrm{~nm}$. a imipramine, $\mathbf{b}$ miconazole c $12.5 \mu \mathrm{M}$ imipramine (IMP) + miconazole. The experiments were performed in triplicate, $n=3$

\section{Conclusion}

In summary, we have demonstrated that imipramine has antileishmanial activity, most likely by affecting the sterol biosynthesis of the parasites. The combination of imipramine with miconazole can improve the 


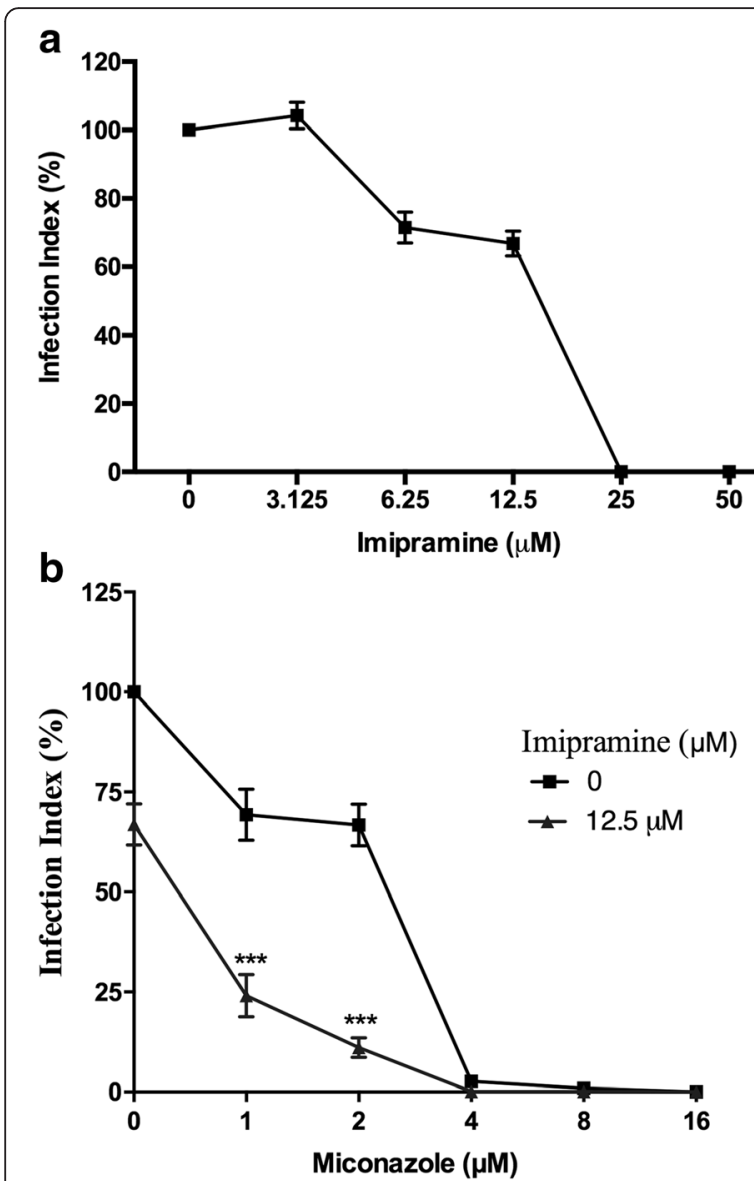

Fig. 3 Antiamastigote activity of the combination of imipramine and miconazole. Peritoneal macrophages infected with L. amazonensis that were left untreated or treated with imipramine and miconazole were incubated for 72 hours at $37^{\circ} \mathrm{C}$. After incubation, the cells were fixed and stained. The infection rate was calculated using the formula: \% infected $M \varnothing \times$ number of amastigotes/total No. $M \varnothing$. a imipramine $\mathbf{b}$ miconazole $+12.5 \mu \mathrm{M}$ imipramine. The experiments were performed in triplicate, $n=3$. The graphs are representative of one experiment, and the standard deviations are shown. ${ }^{*} P<0.05$, ** $P<0.01,{ }^{* * *} P<0.001$

antileishmanial activity. These findings suggest that imipramine could be useful to treat leishmaniasis, particularly if used in combination with other inhibitors of sterol biosynthesis.

\section{Competing interests}

The authors declare that they have no competing interests.

\section{Authors' contributions}

All authors read and approved the final version of the manuscript. WAN, MMCC and ECTS conceived and designed the assays. WAN and TMP performed the experiments. WAN, TMP, MMCC and ECTS analyzed the data. WAN and ECTS contributed to the writing of the manuscript.

\section{Acknowledgments}

TMP and ECTS are CNPq fellows. WAN is a CAPES fellow. ECTS received a grant from the Programa Estratégico de Apoio à Pesquisa em Saúde, FIOCRUZ (PAPES/CNPq; grant 407680/2012-8).
Received: 21 February 2016 Accepted: 21 March 2016

Published online: 31 March 2016

\section{References}

1. Jhingran A, Chatterjee M, Madhubala R. Leishmaniasis: epidemiological trends and diagnosis. In: Myler PJ, Fasel N, editors. Leishmania - After the genome. USA: Caister Academic Press; 2008. p. 1-14.

2. Marra F, Chiappetta MC, Vincenti V. Ear, nose and throat manifestations of mucocutaneous Leishmaniasis: a literature review. Acta Biomed. 2014; 85(1):3-7.

3. Neuber H. Leishmaniasis. J Dtsch Dermatol Ges. 2008;6:754-64.

4. Alvar J, Velez ID, Bern C, Herrero M, Desjeux P, Cano J, Jannin J, den Boer M; WHO Leishmaniasis Control Team. WHO Leishmaniasis Control Team: Leishmaniasis Worldwide and Global Estimates of Its Incidence. Plos One. 2012;7(5):e3567.

5. Sundar S, Chakravarty J. Leishmaniasis: an update of current pharmacotherapy. Expert Opinion on Pharmacother. 2013;14:53-63.

6. Oliveira LF, Schubach AO, Martins MM, Passos SL, Oliveira RV, Marzochi MC, Andrade CA. Systematic review of the adverse effects of cutaneous leishmaniasis treatment in the New World. Acta Trop. 2011;118:87-96.

7. Singh N, Chatterjee M, Sundar S. The overexpression of genes of thiol metabolism contribute to drug resistance in clinical isolates of visceral leishmaniasis (kala azar) in India. Parasit Vectors. 2014;17:7-596.

8. Kesselheim AS, Maggs $L R$, Sarpatwari A. Experience with the priority review voucher program for drug development. JAMA. 2015;314:1687-8.

9. Rijal S, Ostyn B, Uranw S, Rai K, Bhattarai NR, Dorlo TP, Beijnen JH, Vanaerschot M, Decuypere S, Dhakal SS, Das ML, Karki P, Singh R, Boelaert $\mathrm{M}$, Dujardin JC. Increasing failure of Miltefosine in the treatment of Kala-azar in Nepal and the potential role of parasite drug resistance, reinfection, or noncompliance. Clin Infect Dis. 2013;56:1530-8.

10. de Matos Guedes HL, da Silva Costa BL, Chaves SP, de Oliveira Gomes DC, Nosanchuk JD, De Simone SG, Rossi-Bergmann B. Intranasal vaccination with extracellular serine proteases of Leishmania amazonensis confers protective immunity to BALB/C mice against infection. Parasit Vectors. 2014;7:448.

11. Obonaga R, Fernández OL, Valderrama L, Rubiano LC, Castro Mdel M, Barrera MC, Gomez MA, Gore Saravia N. Treatment failure and Miltefosine susceptibility in dermal leishmaniasis caused by Leishmania subgenus Viannia species. Antimicrob Agents Chemother. 2014;58(1):144-52.

12. Racagni $G$, Popoli M. The pharmacological properties of antidepressants. Int Clin Psychopharmacol. 2010;25(3):117-31.

13. Kenis $\mathrm{G}$, Maes $\mathrm{M}$. Effects of antidepressants on the production of cytokines. Int J Neuropsychopharmacol. 2002;5(4):401-12.

14. Jeon SH, Kim SH, Kim Y, Kim YS, Lim Y, Lee YH, Shin SY. The tricyclic antidepressant imipramine induces autophagic cell death in U-87 MG glioma cells. Biochem Biophys Res Commun. 2011;413(2):311-7.

15. Zilberstein D, Dwyer DM. Antidepressants cause lethal disruption of membrane function in the human protozoan parasite Leishmania. Science. 1984;226(4677):977-9.

16. Mukherjee S, Mukherjee B, Mukhopadhyay R, Naskar K, Sundar S, Dujardin JC, Das AK, Roy S. Imipramine is an orally active drug against both antimony sensitive and resistant Leishmania donovani clinical isolates in experimental infection. PLoS Negl Trop Dis. 2012;6(12):e1987.

17. Fisar Z. Interactions between tricyclic antidepressants and phospholipid bilayer membranes. Gen Physiol Biophys. 2005;24(2):161-80.

18. Zimmermann N, Zschocke J, Perisic T, Yu S, Holsboer F, Rein T. Antidepressants inhibit DNA methyltransferase 1 through reducing G9a levels. Biochem J. 2012;448(1):93-102.

19. Ahyayauch $H$, Bennouna M. Interaction of chlorpromazine and imipramine with model membranes. Therapie. 1999:54(5):585-8.

20. Roberts CW, McLeod R, Rice DW, Ginger M, Chance ML, Goad LJ. Fatty acid and sterol metabolism: potential antimicrobial targets in apicomplexan and trypanosomatid parasitic protozoa. Mol Biochem Parasitol. 2003;126:129-42.

21. Rodrigues JC, Attias M, Rodriguez C, Urbina JA, Souza W. Ultrastructural and biochemical alterations induced by 22,26-azasterol, a delta(24(25))-sterol methyltransferase inhibitor, on promastigote and amastigote forms of Leishmania amazonensis. Antimicrob Agents Chemother. 2002;46(2):487-99.

22. Vannier-santos MA, Urbina JA, Martiny A, Neves A, de Souza W. Alterations induced by the antifungal compounds Ketoconazole and Terbinafine in Leishmania. J of Eukaryot Microbiol. 1995;42:337-46. 
23. Haughan PA, Chance ML, Goad LJ. Synergism In vitro of Lovastatin and Miconazole as antileishmanial agents. Biochem Pharmacol. 1992;44: 2199-206.

24. Berman JD, Holz GG, Beach DH. Effects of Ketoconazole on growth and sterol biosynthesis of Leishmania mexicana promastigotes in culture. Mol Biochem Parasitol. 1984;12:1-13.

25. Macedo-Silva ST, Urbina JA, de Souza W, Rodrigues JC. In Vitro activity of the antifungal azoles Itraconazole and Posaconazole against Leishmania amazonensis. PLoS One. 2013;8(12):e83247.

26. Lorente SO, Rodrigues JC, Jiménez Jiménez C, Joyce-Menekse M, Rodrigues C, Croft SL, Yardley V, de Luca-Fradley K, Ruiz-Pérez LM, Urbina J, de Souza W, González Pacanowska D, Gilbert, LH. Novel azasterols as potential agents for treatment of leishmaniasis and trypanosomiasis. Antimicrob Agents Chemother. 2004;48(8):2937-50.

27. Odds FC. Synergy, antagonism, and what the chequerboard puts between them. J Anticrob Chemother. 2003;52(1):1.

28. Bligh EG, Dryer MJ. A rapid method of total lipid extraction and purification. Can J Biochem Physiol. 1959;37(8):911-3.

29. Torres-Santos EC, Sampaio-Santos MI, Buckner FS, Yokoyama K, Gelb M, Urbina JA, Rossi-Bergmann B. Altered sterol profile induced in Leishmania amazonensis by a natural dihydroxymethoxylated chalcone. J Antimicrob Chemother. 2009:63:469-72.

30. Zilberstein D, Liveanu V, Gepstein A. Tricyclic drugs reduce proton motive force in Leishmania donovani promastigotes. Biochem Pharmacol. 1990; 39(5):935-40.

31. Kubera M, Kenis G, Bosmans E, Kajta M, Basta-Kaim A, Scharpe S, Budziszewska B, Maes M. Stimulatory effect of antidepressants on the production of IL-6. Int Immunopharmacol. 2004;4(2):185-92.

32. Giraud F, Claret M, Bruckdorfer KR, Chailley B. The effects of membrane lipid order and cholesterol on the internal and external cationic sites of the Na +-K+ pump in erythrocytes. Biochim Biophys Acta. 1981;647(2): 249-58.

33. Melzacka $M$, Janczar $L$, Nocon $H$. The effects of imipramine on the methylation of phosphatidylethanolamine (PE) in the cortical membranes of Wistar rats. Biochem Pharmacol. 1993;46(3):449-53.

34. Hoo JJ, Noldt P, Beckermann WJ, Agarwal DP, Goedde HW. In vitro effect of haloperidol, chlorpromazine, imipramine and lithium on the erythrocyte catechol-O-methyltransferase. Arzneimittelforschung. 1982;32(6):681-3.

35. Haughan PA, Chance ML, Goad L. Effects of an azasterol inhibitor of sterol 24-transmethylation on sterol biosynthesis and growth of Leishmania donovani promastigotes. Biochem J. 1995;308:31-8.

36. Gigante F, Kaiser M, Brun R, Gilbert IH. SAR studies on azasterols as potential anti-trypanosomal and anti-leishmanial agents. Bioorg Med Chem. 2009:17(16):5950-61.

37. Magaraci F, Jimenez CJ, Rodrigues C, Rodrigues JC, Braga MV, Yardley V, de Luca-Fradley K, Croft SL, de Souza W, Ruiz-Perez LM, Urbina J, Gonzalez Pacanowska D, Gilbert IH. Azasterols as inhibitors of sterol 24methyltransferase in Leishmania species and Trypanosoma cruzi. J Med Chem. 2003;46(22):4714-27.

38. Medina JM, Rodrigues JCF, De Souza W, Atella GC, Barrabin H. Tomatidine promotes the inhibition of 24-alkylated sterol biosynthesis and mitochondrial dysfunction in Leishmania amazonensis promastigotes. Parasitology. 2012;139:1253-65.

39. Bastin P, Stephan A, Raper J, Saint-Remy JM, Opperdoes FR, Courtoy PJ. An $M(r)$ 145,000 low-density lipoprotein (LDL)-binding protein is conserved throughout the Kinetoplastida order. Mol Biochem Parasitol. 1996;76:43-56.

40. Andrade-Neto W, Cicco NN, Cunha-Junior EF, Canto-Cavalheiro MM, Atella GC, Torres-Santos EC. The pharmacological inhibition of sterol biosynthesis in Leishmania is counteracted by enhancement of LDL endocytosis. Acta Trop. 2011;119:194-8.

41. Howe D, Heinzen RA. Coxiella burnetii inhabits a cholesterol-rich vacuole and influences cellular cholesterol metabolism. Cell Microbiol. 2006;8(3):496-507.

42. Underwood KW, Andemariam B, McWilliams GL, Liscum L. Quantitative analysis of hydrophobic amine inhibition of intracellular cholesterol transport. J Lipid Res. 1996;37(7):1556-68.

\section{Submit your next manuscript to BioMed Central and we will help you at every step:}

- We accept pre-submission inquiries

- Our selector tool helps you to find the most relevant journal

- We provide round the clock customer support

- Convenient online submission

- Thorough peer review

- Inclusion in PubMed and all major indexing services

- Maximum visibility for your research

Submit your manuscript at www.biomedcentral.com/submit

) Biomed Central 